\title{
Preserved coronary arteriolar dilatation in patients with type 2 diabetes mellitus: Implications for reactive oxygen species
}

\author{
Zsolt Bagi ${ }^{1,2}$, Attila Feher², ${ }^{2}$ Timea Beleznai \\ 1Department of Physiology, New York Medical College, 95 Grasslands R. Valhalla, New York 10595, USA \\ ${ }^{2}$ Institute of Cardiology, University of Debrecen, 22 Moricz Zs, Debrecen, 4032, Hungary
}

Correspondence: Zsolt Bagi, e-mail: zsolt_bagi@nymc.edu

\begin{abstract}
:
Type 2 diabetes mellitus is associated with clustering of cardiovascular risk factors that may greatly increase individuals' risk of developing coronary artery disease. Type 2 diabetes is believed to impair coronary function. However, its impact on the vasomotor function of coronary resistance vessels in humans is still debated. Reduced, preserved or even augmented dilations of coronary arterioles have been reported in subjects with type 2 diabetes. Interestingly, recent studies have suggested that reactive oxygen species (ROS), particularly hydrogen peroxide, may compensate for the loss of the vasodilatory function of coronary microvessels during disease development. Recent interventional clinical trials have yielded largely negative results, and there has even been some suggestion of harm caused by attempts to reduce ROS. Thus, it is possible that interference with ROS-related signaling might paradoxically temper the function of coronary microvessels, predisposing patients to myocardial ischemia. In this review, we aim to highlight current findings supporting a potential role for ROS in preserving coronary arteriolar dilation in type 2 diabetes mellitus.
\end{abstract}

Key words: diabetes, coronary, arteriole, $\mathrm{H}_{2} \mathrm{O}_{2}$, antioxidant

\section{Changes in vasomotor function of coronary arterioles in type 2 diabetes}

Type 2 diabetes mellitus is associated with a markedly increased incidence of ischemic heart disease, accounting for approximately $70 \%$ of deaths in the diabetic population [49]. The development of macrovascular disease, such as atherosclerotic plaque formation and atherothrombosis is common among patients with diabetes mellitus, and contributes to the increased incidence of myocardial infarction [4]. Although acute and chronic ischemic syndromes are commonly a result of coronary, flow-limiting, atherosclerotic plaques in epicardial coronary arteries, about 10 to $20 \%$ of patients undergoing cardiac catheterization are found to have normal coronary angiograms [10]. Nitenberg et al. have demonstrated that despite the presence of angiographically normal coronary arteries, the coronary flow reserve is reduced in diabetic patients [38]. Thus, it has been suggested that in diabetes patients, epicardial atherosclerosis may not be the only underlying pathophysiology resulting in abnormal coronary flow reserve, but that a role for the reduced dilatory capacity of coronary microvessels may also exist [37, 38]. 
Strong evidence suggests that coronary microcirculation is compromised in diabetes mellitus $[9,11,12$, $32,44]$. Before the morphological changes take place $[18,19,26,45,57]$, vasomotor dysfunction of microvessels may occur, which is considered to be one of the early alterations that occur in several cardiovascular diseases, as outlined by many recent reviews [ 9 , $11,12,29,32,44]$. In humans with diabetes mellitus, impaired vasomotor function of the large conductance arteries is established [14]. However, a limited number of studies are available describing alterations in vasomotor responses of coronary microvessels in diabetic patients. Similar to findings in the peripheral vessels of type 2 diabetic subjects, an impaired dilatory function of coronary arterioles can also be hypothesized. This idea was supported by a study from Gutterman's laboratory showing impaired dilation of human coronary arterioles in response to hypoxia in diabetic patients [35]. Interestingly, the authors have also found that endothelium-derived hyperpolarizing factor (EDHF)-mediated dilation in response to bradykinin was similar in diabetic and non-diabetic patients [35]. Data from our laboratory showed an enhanced bradykinin-induced dilation of coronary microvessels dissected from the hearts of diabetic patients [47] and also in coronary arterioles from patients suffering from obesity and hypertension [21]. In line with these observations, there are other reports showing preserved [24, 30] and even augmented [39] coronary dilations in animal models of type 2 diabetes. In part, these apparently conflicting data can be explained by species differences, the size of coronary vessels studied, the duration of type 2 diabetes and the degree of hyperglycemia. To address some of these controversial findings, it has recently been suggested by Tune et al. that, as compared to the vascular beds of the periphery, coronary microvessels are more "resistant" to changes in the vasomotor function in diseases [29]. This suggests that coronary vessels possess mechanisms that can operate efficiently to protect vasomotor function, such as maintaining vasodilatory responses and/or limiting vasoconstrictor pathways. Indeed, under physiological conditions in the coronary arteriole, many potent vasoconstrictors of the periphery such as norepinephrine and angiotensin II, can cause substantial vasodilation $[46,58]$. On the basis of recent studies, we propose that coronary arterioles exhibit effective mechanisms that can compensate for the loss of vasodilator pathways in type 2 diabetes $[21,47]$.

\section{Impact of oxidative stress on endothelium-dependent vasomotor function in coronary arterioles}

Oxidative stress occurring in response to hyperglycemia [1, 2, 5, 42], hyperinsulinemia [17] and hypertension $[27,50,51]$ is considered to be one of the key factors leading to microvascular disease in patients with type 2 diabetes mellitus. Strong evidence supports that type 2 diabetes is associated with an increased production of reactive oxygen species (ROS) that, via interfering with nitric oxide $(\mathrm{NO})$ signaling, are responsible for the reduced bioavailability of $\mathrm{NO}$ [48]. In this context, we demonstrated previously that in type 2 diabetic rats, vascular production of ROS is markedly elevated due to the increased activity of vascular xanthine oxidase activity. This phenomenon results in impaired NO availability and consequently, reduced agonist-induced dilations of skeletal muscle microvessels [16]. Interestingly, in the same animal model, we observed that, in spite of the reduced NO bioavailability, dilation of coronary arterioles to $\mathrm{ACh}$ is preserved [28]. These findings indicate the possibility that in coronary arterioles of type 2 diabetic rats, unlike in peripheral arterioles, mechanisms intrinsic to the vascular wall are activated to compensate for the reduced NO availability and preserve vasodilation, although the nature of these mechanisms is not completely understood.

Emerging evidence indicates that ROS act in the vasculature by modulating specific redox-sensitive signal transduction pathways under normal and pathological conditions [22, 31]. For instance, Matoba et al. demonstrated that a major dilation factor released from the endothelium of porcine coronary microvessels is the ROS derivate, $\mathrm{H}_{2} \mathrm{O}_{2}$ [33]. Coronary arterial microvessels from the human heart - likely to be affected by existing disease - also generate $\mathrm{H}_{2} \mathrm{O}_{2}$ from endothelial cells, as a major contributor to coronary arteriolar dilation [34]. In this context, we have demonstrated that mice with type 2 diabetes exhibit markedly increased $\mathrm{H}_{2} \mathrm{O}_{2}$ production in the arteriolar wall [15]. Thus, in addition to inhibiting endothelial generation of $\mathrm{NO}, \mathrm{H}_{2} \mathrm{O}_{2}$ may actively participate in endothelium-dependent vasodilation mechanisms in type 2 diabetes mellitus. The mechanism of $\mathrm{H}_{2} \mathrm{O}_{2}$-mediated dilation is not completely understood, but studies have shown that, by activating calcium-activated potassium channels, $\mathrm{H}_{2} \mathrm{O}_{2}$ hyperpolarizes vascular 
smooth muscle cells and therefore potentially acts as an EDHF [13, 33, 34]. Other studies have demonstrated that $\mathrm{H}_{2} \mathrm{O}_{2}$-induced vasodilation is mediated through the release of NO from the endothelium [25] or is partially mediated by cGMP release [20]. Regardless of the mechanisms of action, $\mathrm{H}_{2} \mathrm{O}_{2}$ can be considered a key molecule involved in the mechanism of compensation for the loss of NO-mediation of coronary microvessels during the development of type 2 diabetes mellitus.

\section{Impact of oxidative stress on coronary arteriolar smooth muscle cells - a role for soluble guanylate cyclase activation}

Brandes et al. reported that both acute cessation of endothelial NO production in wild type mice and chronic deficiency of NO in eNOS knockout mice increase the NO sensitivity of vascular smooth muscle cells in response to nitrovasodilator agents [6]. They proposed that an enhanced sensitivity of soluble guanylate cyclase (sGC) to NO may compensate for the reduced NO availability [6]. In this context, it has been also found that administration of exogenous NO decreased sGC activity acutely and decreased its protein expression over time [43]. These findings indicate that NO may play an important regulatory role on the catalytic activity of the $\mathrm{sGC}$; hence, any reduction of NO level may lead to an enhancement of the sensitivity of sGC to NO. In this context, results from our laboratory have provided evidence for enhanced NO sensitivity of coronary arterioles isolated from type 2 diabetic rats, in which we also found reduced $\mathrm{NO}$ bioavailability [28]. Interestingly, we have obtained similar results in humans, demonstrating that coronary arteriole, and also brachial artery, dilations in response to a NO donor are enhanced in patients suffering from obesity and hypertension [21]. Enhanced dilations of coronary arteries in response to the NO donor sodium nitroprusside have been also described in female pigs fed a high fat diet, whereas NOmediated coronary dilations in response to bradykinin were blunted [56]. Collectively, these data suggest that an impaired NO availability in coronary microvessels may be associated with an enhanced sensitivity to NO and that this mechanism may be responsi- ble, in part, for the maintained dilation capacity of coronary arterioles in type 2 diabetes.

An intriguing question thus arises: what are the exact origin and nature of the factor(s) that contribute to the enhanced vascular sensitivity to NO? It seems plausible that the lack of NO may lead to enhanced sGC activity in vascular smooth muscle cells [6]. Although it has been proposed that oxidative and/or nitrosative stress can lead to inactivation of $\mathrm{sGC}$ in long-term [36], other studies have demonstrated that acute exposure to $\mathrm{H}_{2} \mathrm{O}_{2}$ can lead to activation of $\mathrm{sGC}$, contributing to the relaxation of the bovine pulmonary artery [7, 55]. Moreover, Bauersachs et al. have shown that myocardial infarct-induced ischemic heart failure in rats leads to the upregulation of both vascular eNOS and sGC expression in association with an increased vascular superoxide production [3]. Thus, it is likely that ROS, in addition to the above described effect on NO availability, may play a role in the activation of $\mathrm{sGC}$ in the coronary microvessels, a hypothesis which has yet to be tested. Furthermore, it remains unclear to what extent and for how long upregulation of $\mathrm{sGC}$ can contribute to the maintenance of NO-mediated arteriolar vasomotor responses.

\section{Clinical implications}

The above-described studies suggest that in type 2 diabetes mellitus, oxidative stress in the coronary microvascular wall may not only be an undesirable by-product, but a homeostatic response to the "diabetic" environment. Although high levels of ROS have been shown to impair vascular function in several pathological conditions, and that oxidative stress can be considered a negative modulator of vasomotor function [8], recent interventional clinical trials yielded largely negative results in response to antioxidant treatment, with some suggestion of potential harm [54]. For example, the Heart Outcomes Prevention Evaluation (HOPE) trial assessed vitamin-E treatment in high-risk patients with cardiovascular disease and diabetes mellitus and found no effect on cardiovascular outcomes [23]. Worse, the Alpha-Tocopherol, Beta-Carotene Cancer Prevention (ATBC) trial found an increased risk for coronary events in subjects receiving vitamin-E or beta-carotene as antioxidants $[40,41,52]$. Of greater concern was that an 
increased degree of harm from supplemental vitamin-E, vitamin-A, and beta-carotene was indicated by a metaanalysis of 15 clinical trials on cardiovascular outcome [53]. Thus, it is possible that interfering with ROS-dependent vascular responses may add further burden to those mechanisms that maintain vascular functions in diseased conditions. Further studies are needed to solve the current paradox of the roles of oxidative stress, antioxidants and cardiovascular risk in type 2 diabetes mellitus.

In summary, we propose that ROS, particularly $\mathrm{H}_{2} \mathrm{O}_{2}$, may compensate for the reduced NO availability in humans with type 2 diabetes mellitus, thereby contributing to the maintenance of coronary arteriole dilation. By interfering with ROS-related vascular signaling mechanisms, e.g. the administration of antioxidants such as vitamin-E, might paradoxically temper the vasodilatory function of coronary microvessels, predisposing diabetic patients to myocardial ischemia.

\section{Acknowledgment:}

This work is supported by grants from the American Heart Association (0735540T) and by the Hungarian National Science Research Fund (F-048837).

\section{References:}

1. Bagi Z, Koller A: Lack of nitric oxide mediation of flow-dependent arteriolar dilation in type I diabetes is restored by sepiapterin. J Vasc Res, 2003, 40, 47-57.

2. Bagi Z, Toth E, Koller A, Kaley G: Microvascular dysfunction after transient high glucose is caused by superoxide-dependent reduction in the bioavailability of NO and BH(4). Am J Physiol Heart Circ Physiol, 2004, 287, H626-633.

3. Bauersachs J, Bouloumie A, Fraccarollo D, Hu K, Busse R, Ertl G: Endothelial dysfunction in chronic myocardial infarction despite increased vascular endothelial nitric oxide synthase and soluble guanylate cyclase expression: role of enhanced vascular superoxide production. Circulation, 1999, 100, 292-298.

4. Beckman JA, Creager MA, Libby P: Diabetes and atherosclerosis: epidemiology, pathophysiology, and management. JAMA, 2002, 287, 2570-2581.

5. Bohlen HG, Lash JM: Topical hyperglycemia rapidly suppresses EDRF-mediated vasodilation of normal rat arterioles. Am J Physiol, 1993, 265, H219-225.

6. Brandes RP, Kim D, Schmitz-Winnenthal FH, Amidi M, Gödecke A, Mülsch A, Busse R: Increased nitrovasodilator sensitivity in endothelial nitric oxide synthase knock- out mice: role of soluble guanylyl cyclase. Hypertension, 2000, 35, 231-236.

7. Burke TM, Wolin MS: Hydrogen peroxide elicits pulmonary arterial relaxation and guanylate cyclase activation. Am J Physiol, 1987, 252, H721-732.

8. Cai H, Harrison DG: Endothelial dysfunction in cardiovascular diseases: the role of oxidant stress. Circ Res, 2000, 87, 840-844.

9. Camici PG, Crea F: Coronary microvascular dysfunction. N Engl J Med, 2007, 356, 830-840.

10. Cannon RO, 3rd, Camici PG, Epstein SE: Pathophysiological dilemma of syndrome X. Circulation, 1992, 85, 883-892.

11. Cersosimo E, DeFronzo RA: Insulin resistance and endothelial dysfunction: the road map to cardiovascular diseases. Diabetes Metab Res Rev, 2006, 22, 423-436.

12. Creager MA, Luscher TF, Cosentino F, Beckman JA: Diabetes and vascular disease: pathophysiology, clinical consequences, and medical therapy: Part I. Circulation, 2003, 108, 1527-1532.

13. Cseko C, Bagi Z, Koller A: Biphasic effect of hydrogen peroxide on skeletal muscle arteriolar tone via activation of endothelial and smooth muscle signaling pathways. J Appl Physiol, 2004, 97, 1130-1137.

14. De Vriese AS, Verbeuren TJ, Van de Voorde J, Lameire $\mathrm{NH}$, Vanhoutte PM: Endothelial dysfunction in diabetes. Br J Pharmacol, 2000, 130, 963-974.

15. Erdei N, Bagi Z, Edes I, Kaley G, Koller A: $\mathrm{H}_{2} \mathrm{O}_{2}$ increases production of constrictor prostaglandins in smooth muscle leading to enhanced arteriolar tone in Type 2 diabetic mice. Am J Physiol Heart Circ Physiol, 2007, 292, H649-656.

16. Erdei N, Tóth A, Pásztor ET, Papp Z, Edes I, Koller A, Bagi Z.: High-fat diet-induced reduction in nitric oxidedependent arteriolar dilation in rats: role of xanthine oxidase-derived superoxide anion. Am J Physiol Heart Circ Physiol, 2006, 291, H2107-2115.

17. Erdos B, Miller AW, Busija DW: Impaired endotheliummediated relaxation in isolated cerebral arteries from insulin-resistant rats. Am J Physiol Heart Circ Physiol, 2002, 282, H2060-2065.

18. Frisbee JC: Remodeling of the skeletal muscle microcirculation increases resistance to perfusion in obese Zucker rats. Am J Physiol Heart Circ Physiol, 2003, 285, H104-111.

19. Frisbee JC: Obesity, insulin resistance, and microvessel density. Microcirculation, 2007, 14, 289-298.

20. Fujimoto S, Asano T, Sakai M, Sakurai K, Takagi D, Yoshimoto N, Itoh T: Mechanisms of hydrogen peroxide-induced relaxation in rabbit mesenteric small artery. Eur J Pharmacol, 2001, 412, 291-300.

21. Fulop T, Jebelovszki E, Erdei N, Szerafin T, Forster T, Edes I, Koller A, Bagi Z: Adaptation of vasomotor function of human coronary arterioles to the simultaneous presence of obesity and hypertension. Arterioscler Thromb Vasc Biol, 2007, 27, 2348-2354.

22. Gutierrez J, Ballinger SW, Darley-Usmar VM, Landar A: Free radicals, mitochondria, and oxidized lipids: the emerging role in signal transduction in vascular cells. Circ Res, 2006, 99, 924-932. 
23. Hegele RA: Angiotensin-converting enzyme (ACE) inhibition in the secondary prevention of vascular disease: the Heart Outcomes Prevention Evaluation (HOPE) Trial and its substudies. Curr Atheroscler Rep, 2000, 2 , 361-362.

24. Henderson KK, Turk JR, Rush JW, Laughlin MH: Endothelial function in coronary arterioles from pigs with early-stage coronary disease induced by high-fat, high-cholesterol diet: effect of exercise. J Appl Physiol, 2004, 97, 1159-1168.

25. Hirai T, Tsuru H, Tanimitsu N, Takumida M, Watanabe $\mathrm{H}$, Yajin K, Sasa M: Effect of hydrogen peroxide on guinea pig nasal mucosa vasculature. Jpn J Pharmacol, 2000, 84, 470-473.

26. Hodnett BL, Hester RL: Regulation of muscle blood flow in obesity. Microcirculation, 2007, 14, 273-288.

27. Jaap AJ, Shore AC, Tooke JE: The influence of hypertension on microvascular blood flow and resistance to flow in the skin of patients with type 2 (non-insulindependent) diabetes. Diabet Med, 1994, 11, 883-887.

28. Jebelovszki E, Kiraly C, Erdei N, Feher A, Pasztor ET, Rutkai I, Forster T et al.: High-fat diet-induced obesity leads to increased NO sensitivity of rat coronary arterioles: role of soluble guanylate cyclase activation. Am J Physiol Heart Circ Physiol, 2008, 294, H2558-2564.

29. Knudson JD, Dincer UD, Bratz IN, Sturek M, Dick GM, Tune JD: Mechanisms of coronary dysfunction in obesity and insulin resistance. Microcirculation, 2007, 14, 317-338.

30. Knudson JD, Rogers PA, Dincer UD, Bratz IN, Araiza AG, Dick GM, Tune JD: Coronary vasomotor reactivity to endothelin-1 in the prediabetic metabolic syndrome. Microcirculation, 2006, 13, 209-218.

31. Kunsch C, Medford RM: Oxidative stress as a regulator of gene expression in the vasculature. Circ Res, 1999, 85, 753-766.

32. Luscher TF, Creager MA, Beckman JA, Cosentino F: Diabetes and vascular disease: pathophysiology, clinical consequences, and medical therapy: Part II. Circulation, 2003, 108, 1655-1661.

33. Matoba T, Shimokawa H, Morikawa K, Kubota H, Kunihiro I, Urakami-Harasawa L, Mukai L et al.: Electron spin resonance detection of hydrogen peroxide as an endothelium-derived hyperpolarizing factor in porcine coronary microvessels. Arterioscler Thromb Vasc Biol, 2003, 23, 1224-1230.

34. Miura H, Bosnjak JJ, Ning G, Saito T, Miura M, Gutterman DD: Role for hydrogen peroxide in flowinduced dilation of human coronary arterioles. Circ Res, 2003, 92, e31-40.

35. Miura H, Liu Y, Gutterman DD: Human coronary arteriolar dilation to bradykinin depends on membrane hyperpolarization: contribution of nitric oxide and $\mathrm{Ca}^{2+}$-activated $\mathrm{K}^{+}$channels. Circulation, 1999, 99, 3132-3138.

36. Munzel T, Daiber A, Ullrich V, Mulsch A: Vascular consequences of endothelial nitric oxide synthase uncoupling for the activity and expression of the soluble guanylyl cyclase and the cGMP-dependent protein kinase. Arterioscler Thromb Vasc Biol, 2005, 25, $1551-1557$.
37. Nahser PJ, Jr., Brown RE, Oskarsson H, Winniford MD, Rossen JD: Maximal coronary flow reserve and metabolic coronary vasodilation in patients with diabetes mellitus. Circulation, 1995, 91, 635-640.

38. Nitenberg A, Valensi P, Sachs R, Dali M, Aptecar E, Attali JR: Impairment of coronary vascular reserve and ACh-induced coronary vasodilation in diabetic patients with angiographically normal coronary arteries and normal left ventricular systolic function. Diabetes, 1993, 42, 1017-1025.

39. Prakash R, Mintz JD, Stepp DW: Impact of obesity on coronary microvascular function in the Zucker rat. Microcirculation, 2006, 13, 389-396.

40. Rapola JM, Virtamo J, Haukka JK, Heinonen OP, Albanes D, Taylor PR, Huttunen JK: Effect of vitamin E and beta carotene on the incidence of angina pectoris. A randomized, double-blind, controlled trial. JAMA, 1996, 275, 693-698.

41. Rapola JM, Virtamo J, Ripatti S, Haukka JK, Huttunen JK, Albanes D, Taylor PR, Heinonen OP: Effects of alpha tocopherol and beta carotene supplements on symptoms, progression, and prognosis of angina pectoris. Heart, 1998, 79, 454-458.

42. Ruderman NB, Williamson JR, Brownlee M: Glucose and diabetic vascular disease. FASEB J, 1992, 6, 2905-2914.

43. Scott WS, Nakayama DK: Sustained nitric oxide exposure decreases soluble guanylate cyclase mRNA and enzyme activity in pulmonary artery smooth muscle. J Surg Res, 1998, 79, 66-70.

44. Sowers JR, Epstein M, Frohlich ED: Diabetes, hypertension, and cardiovascular disease: an update. Hypertension, 2001, 37, 1053-1059.

45. Stepp DW, Belin De Chantemele EJ: Structural remodeling in the limb circulation: impact of obesity and diabetes. Microcirculation, 2007, 14, 311-316.

46. Sun D, Huang A, Mital S, Kichuk MR, Marboe CC, Addonizio LJ, Michler RE et al.: Norepinephrine elicits beta2-receptor-mediated dilation of isolated human coronary arterioles. Circulation, 2002, 106, 550-555.

47. Szerafin T, Erdei N, Fulop T, Pasztor ET, Edes I, Koller A, Bagi Z: Increased cyclooxygenase-2 expression and prostaglandin-mediated dilation in coronary arterioles of patients with diabetes mellitus. Circ Res, 2006, 99, e12-17.

48. Triggle CR, Ding H, Anderson TJ, Pannirselvam M: The endothelium in health and disease: a discussion of the contribution of non-nitric oxide endothelium-derived vasoactive mediators to vascular homeostasis in normal vessels and in type II diabetes. Mol Cell Biochem, 2004, 263, 21-27.

49. Turner RC, Millns H, Neil HA, Stratton IM, Manley SE, Matthews DR, Holman RR: Risk factors for coronary artery disease in non-insulin dependent diabetes mellitus: United Kingdom Prospective Diabetes Study (UKPDS: 23). BMJ, 1998, 316, 823-828.

50. Ungvari Z, Csiszar A, Huang A, Kaminski PM, Wolin MS, Koller A: High pressure induces superoxide production in isolated arteries via protein kinase C-dependent activation of NAD(P)H oxidase. Circulation, 2003, 108, 1253-1258. 
51. Ungvari Z, Csiszar A, Kaminski PM, Wolin MS, Koller A: Chronic high pressure-induced arterial oxidative stress: involvement of protein kinase $\mathrm{C}$-dependent NAD $(\mathrm{P}) \mathrm{H}$ oxidase and local renin-angiotensin system. Am J Pathol, 2004, 165, 219-226.

52. Virtamo J, Rapola JM, Ripatti S, Heinonen OP, Taylor PR, Albanes D, Huttunen JK: Effect of vitamin E and beta carotene on the incidence of primary nonfatal myocardial infarction and fatal coronary heart disease. Arch Intern Med, 1998, 158, 668-675.

53. Vivekananthan DP, Penn MS, Sapp SK, Hsu A, Topol EJ: Use of antioxidant vitamins for the prevention of cardiovascular disease: meta-analysis of randomised trials. Lancet, 2003, 361, 2017-2023.

54. Willcox BJ, Curb JD, Rodriguez BL: Antioxidants in cardiovascular health and disease: key lessons from epidemiologic studies. Am J Cardiol, 2008, 101, 75D-86D.

55. Wolin MS, Burke TM: Hydrogen peroxide elicits activation of bovine pulmonary arterial soluble guanylate cyclase by a mechanism associated with its metabolism by catalase. Biochem Biophys Res Commun, 1987, 143, 20-25.

56. Woodman CR, Turk JR, Rush JW, Laughlin MH: Exercise attenuates the effects of hypercholesterolemia on endothelium-dependent relaxation in coronary arteries from adult female pigs. J Appl Physiol, 2004, 96, $1105-1113$.

57. Xiang L, Naik J, Hester RL: Exercise-induced increase in skeletal muscle vasodilatory responses in obese Zucker rats. Am J Physiol Regul Integr Comp Physiol, 2005, 288, R987-991.

58. Zhang C, Hein TW, Wang W, Kuo L: Divergent roles of angiotensin II AT1 and AT2 receptors in modulating coronary microvascular function. Circ Res, 2003, 92, $322-329$.

Received:

December 5, 2008; January 14, 2009. 